\title{
Análise de currículos de ciências à luz da teoria de Bernstein
}

\section{Analysis of science curricula in the light of Bernstein's theory}

Franciele Braz de Oliveira Coelho ${ }^{1}$

\begin{abstract}
Resumo: Esse estudo apresenta uma revisão bibliográfica feita em periódicos da área de Educação, sobre pesquisas que analisaram currículos de Ciências da Natureza com embasamento teórico dos pressupostos sociológicos de Bernstein. Os resultados apontam que pesquisas com esse enfoque vêm sendo desenvolvidas principalmente em Portugal, pelo grupo de Estudos Sociológicos de Sala de Aula (ESSA), da Universidade de Lisboa. Também se verifica que boa parte dos estudos foram desenvolvidos a partir de análises de currículos de Ciências da Educação Básica. A revisão desses estudos mostra que o conceito de recontextualização foi o mais presente nas publicações, em que o discurso pedagógico oficial é analisado em relação ao discurso pedagógico de reprodução dos materiais didáticos, da prática docente e da relação entre a escola e a comunidade. As pesquisas apontam a diminuição da complexidade dos conhecimentos científicos e das competências investigativas no processo de recontextualização.
\end{abstract}

Palavras-chave: Revisão bibliográfica. Discurso pedagógico. Basil Bernstein. Currículo. Ensino de ciências.

\begin{abstract}
This study presents a bibliographical review carried out in periodicals of the Education area, on researches that analysed curricula of Natural Sciences with theoretical foundation of the sociological assumptions of Bernstein. The results point out that the Sociology of Classroom Studies (ESSA), University of Lisbon, has developed researches with this focus mainly in Portugal. It is also verified that the main part of the studies were developed from analyses of curricula of Sciences of Basic Education. The review of these studies shows that the concept of re-contextualization was the most present theme in the publications, in which the official pedagogical discourse is analysed in relation to the pedagogical discourse of reproduction of teaching materials, teaching practice and the relationship between school and community. The research points out the reduction of the complexity of scientific knowledge and investigative skills in the re-contextualization process.
\end{abstract}

Keywords: Bibliographical revision. Pedagogical discourse. Basil Bernstein. Curriculum. Science teaching.

\footnotetext{
${ }^{1}$ Universidade Federal do Pampa (Unipampa), Dom Pedrito, RS, Brasil.

E-mail: < francielecoelho@unipampa.edu.br>
} 


\section{Introdução}

O conceito de currículo tem enfrentado modificações, principalmente decorrentes do contexto vivenciado em cada período da história educacional. Sua análise permite que sejam compreendidos aspectos que possuem relação direta com o processo de construção do conhecimento dos estudantes. Silva, Morais e Neves (2013, p. 179-180) destacam que "O currículo escrito é uma fonte documental que nos proporciona um importante testemunho da estrutura institucionalizada da educação. Ele contém os conhecimentos e as competências a desenvolver pelos alunos, os valores e as normas de conduta social." Pelo currículo, a escola atua ideologicamente, de forma direta por meio de componentes como História e Geografia, os quais são “[...] mais suscetíveis ao transporte de crenças explícitas sobre a desejabilidade das estruturas sociais existentes [...]” (SILVA, 2000, p. 31), ou indireta, por meio de áreas técnicas como a Matemática. Teorias críticas do currículo vão na contramão das teorias tradicionais e, apesar das críticas apontadas nos anos de 1970 e 1980, principalmente pelo determinismo econômico, hoje ainda fundamentam a teorização curricular (SILVA, 2000).

Algumas investigações sobre currículos de Ciências vêm fazendo uso do conceito de dispositivo pedagógico, de Basil Bernstein (BERNSTEIN, 1977, 1990, 1999, 2000), como aporte teórico, principalmente em relação ao processo de recontextualização do currículo, que contempla as transformações que ocorrem no discurso pedagógico oficial (diretrizes, documentos educacionais...) na prática pedagógica e na elaboração de recursos didáticos. Bernstein apresenta uma teoria sociológica do currículo, cujo foco não é o "conteúdo" do currículo, mas as relações estruturais entre os tipos de conhecimento que o formam (SILVA, 2000).

Este estudo é parte de uma pesquisa de doutorado em andamento e, com vistas a uma revisão da literatura sobre currículo à luz das teorias de Bernstein, o estudo teve como objetivo analisar pesquisas desenvolvidas sobre o currículo de Ciências da Natureza no âmbito da Educação Básica e na formação docente da área e que se fundamentaram nos pressupostos sociológicos da teoria de Bernstein. Foram analisados periódicos da área de Educação, contemplando o período de 2010 a 2014, totalizando uma amostra de sete artigos sobre a temática. A seguir, são descritos alguns aspectos da teoria de Bernstein, a metodologia utilizada no estudo e os resultados obtidos na análise.

\section{Aspectos da teoria do dispositivo pedagógico de Bernstein}

A teoria de Bernstein vem sendo utilizada em estudos que buscam analisar currículos, visto que oferece a possibilidade de análise tanto em nível macro, da formulação de políticas educacionais, quanto no nível micro, que engloba as escolas e as salas de aula (AL-RAMAHI; DAVIES, 2002). Bernstein iniciou suas publicações em 1958 e desenvolveu estudos até 2000, ano de sua morte. Suas ideias são descritas em cinco volumes, que apresentam a teoria dos códigos sociais e educativos e suas implicações para a produção social. Seu trabalho "[...] coloca em questão o papel da educação na reprodução cultural das relações de classe, evidenciando que a pedagogia, o currículo e a avaliação são formas de controle social" (MAINARDES; STREMEL, 2010, p. 31).

Para Bernstein, o conceito de dispositivo pedagógico "[...] consiste de um conjunto de regras que regulam internamente a comunicação pedagógica e incidem sobre uma série de 
significados passíveis de serem transmitidos pela escola" (GALIAN, 2011, p. 767). A estabilidade das regras do dispositivo pedagógico possui relação com a distribuição do poder e das formas de manutenção da ordem social; dessa forma, esse conceito não é ideologicamente neutro (GALIAN, 2011). As regras presentes no dispositivo pedagógico são: as regras distributivas, que regulam as relações de poder; as regras recontextualizadoras, que possuem a função de regular a formação do discurso pedagógico específico; as regras de avaliação, que explicitam critérios para a prática (BERNSTEIN, 1998).

O conceito de discurso pedagógico de Bernstein apresenta um princípio de inserção de um discurso instrucional (DI), que possui relação com a transmissão/aquisição de competências específicas, em um discurso regulador (DR), relacionado à transmissão de princípios de ordem moral (BERNSTEIN, 1996).

No campo de Estado, sob a influência do campo internacional, do campo da economia (recursos físicos) e do campo do controle simbólico (recursos discursivos), é produzido o discurso regulador geral (DRG). Como resultado da recontextualização oficial do DRG, designadamente ao nível do Ministério da Educação e suas agências, é produzido o discurso pedagógico oficial (DPO). (FERREIRA; MORAIS, 2010, p. 122).

O discurso pedagógico oficial (DPO) está relacionado ao "que" ensinar e ao "como" ensinar. Com relação ao "que" ensinar, as análises podem se voltar para a verificação do grau de exigência conceitual, a complexidade dos conhecimentos e as competências a serem adquiridas (SILVA; MORAIS; NEVES, 2013). Já com relação ao "como” ensinar, deve-se verificar “[...] as relações que definem os contextos instrucionais e regulador do ensino- aprendizagem" (SILVA; MORAIS; NEVES, 2013, p. 183). Por meio de novos processos de recontextualização, ou seja, das transformações que ocorrem no DPO, surge o denominado "discurso pedagógico de reprodução" (DPR), que é veiculado em livros didáticos (CALADO; NEVES, 2012). O DPR em sala de aula pode ainda sofrer novas recontextualizações, que dependerão do contexto da escola e da prática pedagógica do professor (CALADO; NEVES, 2012). O discurso pedagógico, de acordo com Bernstein (1996), trata-se de um princípio de recontextualização, que se apropria de outros discursos e os adequa conforme sua própria lógica de ordenamento. Por meio da recontextualização, é possível compreender o DPR não como demandas impostas pelo DPO, mas na medida em que é introduzido em diferentes contextos educacionais, é reinterpretado e, assim, recontextualizado (LOPES, 2005). Mesmo em espaços educacionais não formais, como, por exemplo, museus de Ciências, o discurso se dá por meio de recontextualizações (MARANDINO, 2004).

Em seus estudos, Bernstein apresenta, ainda, os conceitos de classificação e enquadramento. As relações de poder e controle do que é ensinado e aprendido são definidas pelo termo classificação e as relações de poder e controle, relacionadas à forma de condução do processo de ensinar e de aprender, são orientadas pelo conceito de enquadramento (MAINARDES; STREMEL, 2010). Para Bernstein (1996), a classificação é considerada forte $\left(C^{+}\right)$quando a delimitação entre conteúdos e áreas do conhecimento é bem demarcada. Quando ocorre o contrário, a classificação é definida como fraca $\left(\mathrm{C}^{-}\right)$. O enquadramento forte $\left(\mathrm{E}^{+}\right)$aponta que o transmissor regula o conteúdo, o sequenciamento, a forma, o compassamento e o discurso no 
processo de aprendizagem. Quando há um enquadramento fraco $\left(\mathrm{E}^{-}\right)$, o transmissor apresenta um menor controle sobre os elementos citados anteriormente, caracterizados como regras hierárquicas, na visão de Bernstein.

Por fim, vale ressaltar outros dois importantes elementos da teoria de Bernstein, que fundamentam alguns estudos voltados à análise de currículos: o discurso vertical e o discurso horizontal, sendo que o discurso horizontal "[...] refere-se ao conhecimento cotidiano ou conhecimento do senso comum [...]” (MAINARDES; STREMEL, 2010, p. 40). O discurso vertical é definido por Bernstein como "[...] estrutura hierárquica orientada no sentido de integrar proposições para operar em níveis de abstração crescentes” (MORAIS; NEVES, 2007 apud GALIAN, 2011, p. 771).

\section{Metodologia}

Por meio de uma abordagem qualitativa do tipo exploratória, que possui como objetivo proporcionar maior familiaridade com o problema, com vistas a torná-lo mais explícito ou a construir hipóteses (GIL, 2007), este estudo buscou elucidar o seguinte problema de pesquisa: De que forma a teoria de Basil Bernstein vem sendo utilizada na análise de currículos da área de Ciências? Assim, foi desenvolvida uma pesquisa bibliográfica, do tipo estado do conhecimento, que é caracterizada por apresentar um estudo descritivo da trajetória e distribuição da produção científica sobre um determinado objeto, estabelecendo relações contextuais com um conjunto de outras variáveis, como data de publicação, temas e periódicos, etc. (UNIVERSITAS, 2002).

No estudo, foram analisadas as publicações de três periódicos da área de Educação, no período de 2010 a 2014: Educação e Pesquisa (Qualis² A1 - Educação); Ciência \& Educação (Qualis A1 - Educação); Revista Portuguesa de Educação (Qualis A2 - Educação). Essa triagem ocorreu depois de uma busca no banco de dados da plataforma Scielo com as palavras-chave: "Bernstein Ciências", em que apenas foram identificados artigos relacionados com o objetivo deste estudo nos periódicos citados, selecionando-se apenas periódicos com Qualis A (A1 e A2). A amostra desta análise é composta por sete estudos que avaliaram currículos de Ciências com base na teoria de Bernstein.

\section{Resultados e discussões}

Após a leitura das sete publicações encontradas, uma primeira análise foi relacionada ao ano de publicação, o que é apresentado no Gráfico 1.

\footnotetext{
${ }^{2}$ Qualis é um sistema de classificação de periódicos organizado pela Coordenação de Aperfeiçoamento de Pessoal de Nível Superior (CAPES). 
Gráfico 1. Número de periódicos sobre o tema, publicados em cada ano no período de 2010 a 2014

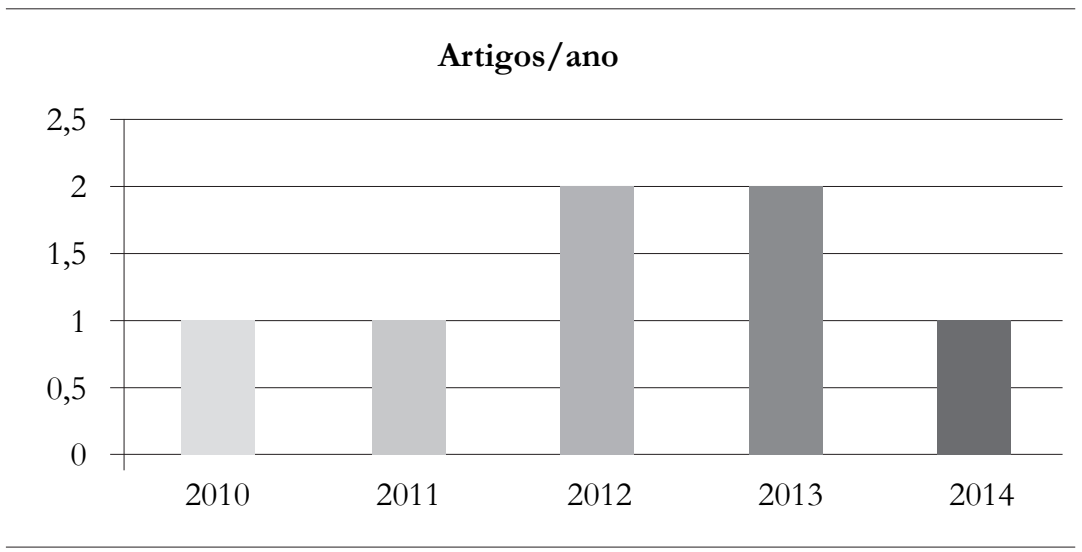

Fonte: elaborado pelos autores a partir dos dados da pesquisa.

No período analisado, verifica-se uma maior concentração de pesquisas envolvendo a análise de currículos de Ciências, com fundamentação na teoria de Bernstein, nos anos de 2012 e 2013, com quatro trabalhos publicados nesse período. A distribuição das publicações sobre o tema, nos periódicos analisados, mostra que a Revista Portuguesa de Educação apresenta o maior número de publicações no intervalo de tempo analisado (4), seguido da Revista Ciência \& Educação (2). A revista Educação e Pesquisa teve apenas a publicação de um artigo sobre o tema no período de 2010 a 2014. O número de publicações envolvendo a análise de currículos, tendo como fundamentação a teoria de Bernstein na Revista Portuguesa de Educação, pode ser explicado visto que, em Portugal, se encontra o Grupo de Estudos Sociológicos de Sala de Aula (ESSA), vinculado ao Centro de Investigação em Educação da Faculdade de Ciências da Universidade de Lisboa, que desenvolve pesquisas na área de Ciências da Natureza, em que muitas apresentam embasamento teórico nas ideias de Bernstein. Destaca-se, no grupo ESSA, as pesquisas envolvendo a análise de currículos de Ciências desenvolvidas por Morais, que é autora de três publicações da amostra analisada nesse estudo.

\section{Currículo e a teoria de Bernstein: análise das publicações da Revista Portuguesa de Educação}

Dos trabalhos publicados na Revista Portuguesa de Educação no período descrito, encontrase a pesquisa sobre a natureza da ciência nos currículos de Ciências, que apresenta um estudo sobre o currículo de Ciências Naturais do $3 .^{\circ}$ ciclo do ensino básico de Portugal (FERREIRA; MORAIS, 2010). A pesquisa analisou em que medida a mensagem sociológica transmitida pelo DPO, veiculado no currículo de Ciências Naturais do 3. ciclo do ensino básico português, contempla a natureza da ciência. O estudo teve como fundamentação teórica os estudos de Bernstein e a visão sobre conceptualização apresentada por Ziman (FERREIRA; MORAIS, 2010). Assim como outras pesquisas analisadas nesse estudo, o trabalho de Ferreira e Morais 
(2010) analisou o documento Currículo Nacional do Ensino Básico - Competências Essenciais - e as Orientações Curriculares para o 3..$^{\circ}$ ciclo do Ensino Básico de Portugal. Em ambos os documentos, foram analisadas as seções referentes à área de Ciências Naturais.

As pesquisas de Calado e Neves (2012) e de Alves e Morais (2013), também publicados na Revista Portuguesa de Educação e analisadas neste estudo, apoiam suas pesquisas na análise dos documentos educacionais de Portugal utilizados na pesquisa de Ferreira e Morais (2010). Em todas as publicações analisadas nesse periódico, os autores explicitam que o ensino básico de Portugal passou por uma reestruturação curricular no período de 2001/2002, com a adoção de uma flexibilização curricular, contemplada com a elaboração dos documentos educacionais descritos anteriormente e utilizados pelos autores em suas pesquisas de análise de currículos.

Ainda sobre o estudo de Ferreira e Morais (2010), a análise do DPO centrou-se em aspectos descritos na teoria de Bernstein, referentes ao "que" e "como" ensinar. Na pesquisa, foram aplicados instrumentos com base em estudos anteriores desenvolvidos pelo grupo ESSA. Os instrumentos foram organizados de forma a contemplar as quatro secções principais de qualquer programa e que correspondem a aspectos do currículo considerados referenciais para o processo de ensino-aprendizagem: (1) Conhecimentos; (2) Finalidades; (3) Orientações Metodológicas; e (4) Avaliação (FERREIRA; MORAIS, 2010). Assim, foram aplicados três instrumentos que buscaram verificar os seguintes aspectos: (1) caracterização do processo de construção da ciência, para avaliar o nível de conceitualização dos conteúdos metacientíficos; (2) conhecimentos e competências cognitivas das dimensões da construção da ciência; (3) avaliação do grau de explicitação dos conhecimentos metacientíficos. Os autores explicitam ainda que, para "[...] cada secção, foram definidos descritivos correspondentes a quatro graus de complexidade dos conteúdos metacientíficos relativos a cada dimensão do processo de construção da ciência” (FERREIRA; MORAIS, 2010, p. 129).

O estudo de Ferreira e Morais (2010) aponta um baixo nível de conceitualização do currículo de ciências, no âmbito das diferentes dimensões metacientíficas. As autoras apontam, como hipóteses para o resultado obtido, o que é definido por Bernstein como discurso horizontal, destacando que o "[...] conhecimento metacientífico, sendo diferente da estrutura hierárquica do conhecimento científico, poderá levantar dificuldades de operacionalização aos autores de currículos de ciências" (FERREIRA; MORAIS, 2010, p. 147).

Outro estudo presente na Revista Portuguesa de Educação, no período analisado, compreende o estudo de processos de recontextualização em currículos e livros didáticos em contexto de flexibilidade curricular (CALADO; NEVES, 2012). A pesquisa analisou a mensagem de dois livros didáticos de Ciências Naturais do 3. ${ }^{\circ}$ ciclo do ensino básico e a caracterização dos processos de recontextualização que ocorrem na mensagem do currículo. Os autores destacam que os professores não possuem o hábito de organizarem sua prática pedagógica a partir dos documentos educacionais, como diretrizes e orientações curriculares, mas orientam seu trabalho a partir do que é proposto em livros didáticos (CALADO; NEVES, 2012). A análise teve como foco quatro características pedagógicas: (1) processo de construção da ciência; (2) intradisciplinaridade ${ }^{3}$, (3) nível de exigência conceitual e, (4) critérios de avaliação (CALADO;

\footnotetext{
${ }^{3}$ As autoras definem intradisciplinaridade como relação entre os conhecimentos científicos e metacientíficos e entre diferentes conhecimentos científicos (CALADO; NEVES, 2012).
} 
NEVES, 2012). A pesquisa revelou um “[...] baixo grau de intradisciplinaridade entre diferentes conhecimentos científicos, condição que favorece o predomínio de conceitos científicos menos abrangentes e que envolvem menos relações entre diferentes conceitos, em detrimento do foco em temas integradores" (CALADO; NEVES, 2012, p. 84).

A pesquisa intitulada "Currículo e práticas pedagógicas - uma análise sociológica de textos e contextos da educação em ciências" (ALVES; MORAIS, 2013) buscou analisar em que medida a mensagem sociológica transmitida pela prática pedagógica de professores de Ciências representa uma recontextualização do DPO veiculado no currículo de Ciências Naturais do 3. ${ }^{\circ}$ ciclo do Ensino Básico português. A análise do DP levou em consideração o "que" e o "como" do processo de ensino aprendizagem. Além dos documentos educacionais do ensino básico de Portugal (Competências Essenciais e Orientações Curriculares), a pesquisa também analisou a prática pedagógica de duas professoras de Ciências (uma de escola privada e uma de escola pública), em que a amostra foi limitada pelo uso de tecnologias de informação e comunicação em sala de aula. A prática pedagógica das professoras foi analisada no estudo, em termos de sua orientação específica de codificação (OEC), caracterizada pela “[...] posse ou não das regras de reconhecimento e de realização para o contexto especifico da aprendizagem científica, no que concerne às mesmas características que foram usadas na análise do currículo" (ALVES; MORAIS, 2013, p. 226).

Alves e Morais (2013, p. 219) enfatizam que os resultados do estudo apontam para “[...] a existência de processos de transformação da mensagem dentro do Ministério da Educação, quando se passa dos princípios gerais do currículo para os princípios específicos do mesmo, no sentido do decréscimo da qualidade da educação científica". Seus resultados também sugerem a ocorrência de uma diminuição da qualidade do processo de ensino aprendizagem, quando se passa do currículo para as práticas pedagógicas.

O estudo sobre (des)continuidades na mensagem pedagógica no currículo de Ciências Naturais no 1. ${ }^{\circ}$ ciclo do Ensino Básico português, elaborado por Silva, Morais e Neves (2013), analisou o currículo de Ciências, verificando as diferenças nas mensagens veiculadas pelos documentos: Competências Essenciais - estudo do Meio e Programa do Estudo do Meio, de Portugal (Figura 1). As autoras destacam que, no 1. ${ }^{\circ}$ ciclo do Ensino Básico português, “[...] permaneceram os programas anteriores à reestruturação curricular, havendo apenas a indicação de que estes programas deveriam ser reinterpretados à luz dos princípios do novo currículo nacional" (SILVA; MORAIS; NEVES, 2013, p. 80).

O estudo teve embasamento em pressupostos psicológicos (Vygotsky) e sociológicos (Bernstein). Assim como nos estudos descritos anteriormente, a pesquisa buscou analisar o "que" e o "como" ensinar, veiculados no DPO. O estudo se deu a partir da organização de unidades de análises, com a aplicação de instrumentos que buscaram verificar aspectos como: complexidade dos conhecimentos científicos; complexidade das competências investigativas; contexto instrucional (relação entre sujeitos); relação entre discursos - intradisciplinares e interdisciplinares; contexto regulador (regras hierárquicas: relação professor-aluno, relação aluno-aluno); relação entre espaços (espaço professor - espaço alunos, espaço dos vários alunos). 
Coelho, F. B. O.

Figura 1. O currículo de Ciências no 1. ${ }^{\circ}$ ciclo do Ensino Básico - Estudo de (des)continuidades na mensagem pedagógica

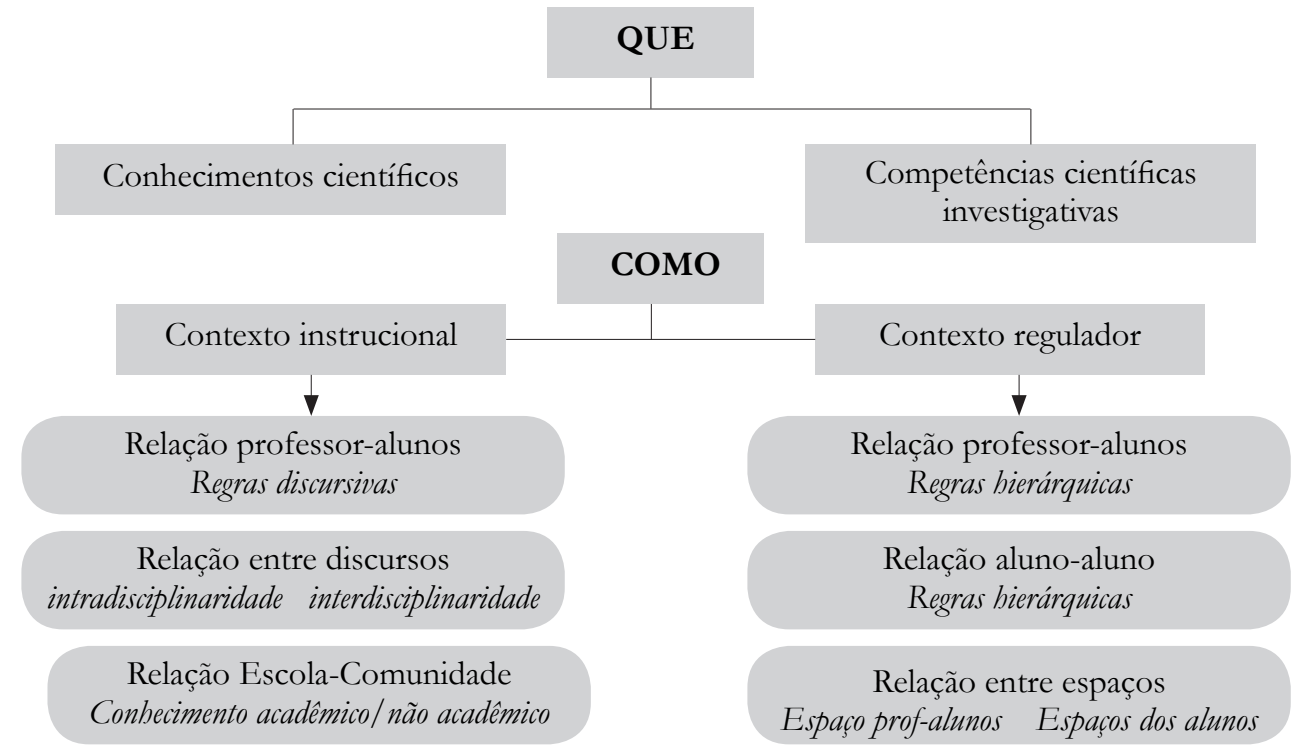

Fonte: Silva, Morais e Neves (2013, p. 187).

Os resultados desse estudo apontam que a complexidade dos conhecimentos e competências investigativas é claramente superior no documento das Competências Essenciais (SILVA; MORAIS; NEVES, 2013). Sobre o aspecto relação professor-alunos, o estudo apontou que, tendo por base os documentos analisados, não é possível indicar com clareza quem deve ter controle. O estudo evidenciou, também, reduzida relação entre os conhecimentos científicos e a fraca relação entre conhecimentos de Ciências com os saberes de outras áreas, em ambos os documentos (SILVA; MORAIS; NEVES, 2013). Os documentos analisados no estudo não veiculam a mesma teoria de instrução, sendo que o Programa do Estudo do Meio privilegia em menor grau a instrução centrada no aluno e o documento Competências Essenciais propõe a adoção de uma pedagogia mista, ora centrada no aluno, ora centrada no professor (SILVA; MORAIS; NEVES, 2013). Os autores apontam que tais diferenças podem refletir "[...] direta e indiretamente, na prática dos professores e, consequentemente, na aprendizagem dos alunos" (SILVA; MORAIS; NEVES, 2013, p. 211).

Com a investigação das publicações da Revista Portuguesa de Educação sobre a análise de currículos de Ciências e a teoria de Bernstein, verifica-se que as pesquisas desenvolvidas em Portugal no período de 2010 a 2014 apoiam seus estudos principalmente nos documentos produzidos na reestruturação curricular do ensino básico (2001/2002). As pesquisas mostram grande preocupação com a verificação da recontextualização definida por Bernstein, destacando-se a análise dos aspectos de "que" e "como" ensinar, presentes no DPO. Além disso, 
Análise de currículos de ciências à luz da teoria de Bernstein

verifica-se também a preocupação, nas pesquisas do grupo de ESSA, sobre a formação docente na área de Ciências, uma vez que seus estudos apontam uma diminuição da complexidade dos conhecimentos científicos e das competências investigativas no processo de recontextualização do DPO para o DPR.

\section{Currículo e a teoria de Bernstein: análise das publicações na Revista Ciência \& educação}

Sobre a temática analisada nesse estudo, a revista Ciência \& Educação apresenta duas publicações no período de 2010 a 2014. Um dos estudos é intitulado "A prática pedagógica e a criação de um contexto favorável para a aprendizagem de Ciências do Ensino Fundamental" (GALIAN, 2012), que analisou as relações discursivas entre professor e alunos, que se expressam na comunicação pedagógica. A pesquisa foi desenvolvida tendo por base os estudos desenvolvidos pelo grupo de ESSA. O estudo teve, como fonte, as observações realizadas em aulas de uma professora de Ciências de $8 .^{a}$ série do Ensino Fundamental, sendo que nesse contexto foi observado um total de 20 aulas.

Na pesquisa de Galian (2012), a relação professor-aluno foi analisada com base nas relações de controle, as quais possuem as seguintes características pedagógicas: seleção; sequência; compassamento; critérios de avaliação. $\mathrm{O}$ estudo também buscou verificar as seguintes seções das aulas observadas: (1) exploração/discussão dos temas em estudo; (2) trabalhos/atividades a realizar; (3) elaboração de sínteses; (4) perguntas dirigidas aos alunos; (5) perguntas dos alunos; e (6) tempo destinado à realização das atividades ou aos registros nos cadernos (GALIAN, 2012). A pesquisa revelou aspectos que potencializam o rebaixamento do nível de exigência conceitual das aulas de ciências. Também ficou evidenciado o papel dos alunos, que atuam no processo de ensino aprendizagem como ouvintes e executores de tarefas (GALIAN, 2012). "Um meio de se manter um nível mais elevado de exigência conceitual do conhecimento escolar de ciências sugerido no movimento de análise dos dados da pesquisa é o cuidado com a prática docente" (GALIAN, 2012, p. 432).

Outro estudo presente na revista é intitulado "El paradigma de la complejidad em discursos sobre formación docente em ciências" (LUNA, 2014). Essa pesquisa analisou discursos sobre a formação de professores de Ciências (principalmente na Argentina), no que se refere à incorporação do paradigma da complexidade como critério de inovação de conteúdos e métodos de ensino (LUNA, 2014). A autora destaca que aspectos das últimas reformas curriculares na Argentina, com relação à formação docente, manifestam a necessidade de melhorias em sua qualidade, a partir da inclusão de perspectivas de Ciência e Tecnologia orientadas pelo paradigma da complexidade, com o objetivo de atualizar o ensino. No estudo foram analisados documentos sobre formação docente em Ciências na Argentina, de procedência oficial e institucional (diretrizes curriculares, recomendações, planos de estudos) e artigos acadêmicos de Didática de Ciências Naturais. Os resultados desse estudo apontam que os documentos omitem os aspectos epistemológicos que historicamente moldaram seus currículos (LUNA, 2014).

A análise das publicações sobre o tema, presente na revista Ciência \& Educação, indica que, em nosso país, poucos estudos voltados ao currículo de Ciências vêm sendo desenvolvidos, mesmo com as mudanças propostas nos documentos educacionais e nas diretrizes da Educação Básica e de Licenciaturas da área, como nos Parâmetros Curriculres Nacionais (PCN) (BRA- 
SIL, 1998), Parâmetros Curriculares Nacionais do Ensino Médio (PCNEM) (BRASIL, 2000), Orientações Educacionais Complementares aos Parâmetros Curriculares Nacionais (PCN+) (BRASIL, 2002), Diretrizes Curriculares Nacionais Gerais da Educação Básica (BRASIL, 2013) e Diretrizes Curriculares Nacionais para formação superior inicial (BRASIL, 2015). O estudo apresentado por Galian (2012) aponta a necessidade de investimento em ações que qualifiquem a prática docente, na formação inicial e continuada desses profissionais. Já a pesquisa desenvolvida na Argentina, apresentada por Luna (2014), aponta outro aspecto importante com relação à formação de professores de Ciências, a necessidade de atualização de métodos e conteúdos, com base no paradigma da complexidade.

\section{Currículo e a teoria de Bernstein: análise das publicações na Revista Educação e Pesquisa}

Com relação à temática abordada neste estudo, no período analisado, foi encontrada apenas uma publicação no periódico Educação e Pesquisa. O estudo descrito contempla a recontextualização e o nível de exigência conceitual do conhecimento escolar (GALIAN, 2011). Essa pesquisa é parte da investigação publicada no periódico Ciência \& Educação, descrito nesta análise no subitem anterior. Galian (2011) focalizou, nesse estudo, as transformações que ocorrem no discurso pedagógico em relação ao nível conceitual do conhecimento e visou ampliar a compreensão do processo de constituição do conhecimento escolar (Figura 2). A investigação teve por base os estudos desenvolvidos pelo grupo de ESSA. Os PCN - Ciências Naturais e um livro didático de Ciências foram suas fontes de análise. O PCN de Ciências Naturais do 4. ${ }^{\circ}$ ciclo representou o DPO no estudo em questão. O livro didático de Ciências, distribuído às escolas pelo Programa Nacional do Livro Didático (BRASIL, 2004) é caracterizado, no estudo, como fruto da recontextualização do DPO pelas editoras e pelos autores, no campo recontextualizador pedagógico (GALIAN, 2011). Para realizar a investigação, foram extraídas 15 unidades de análise (UA), que consistiam em um ou mais períodos com um determinado significado semântico (GALIAN, 2011). Na análise do nível de exigência conceitual, a autora considerou os graus de complexidade das competências e dos conteúdos científicos e o grau de intradisciplinaridade das UA.

Os resultados de Galian (2011) indicam a configuração de um contexto não favorável ao avanço em direção ao pensamento complexo. O estudo revela ainda que a mobilização dos conhecimentos dos alunos não tem funcionado como ponto de partida para os estudos a serem desenvolvidos em sala de aula, mas aparecem como um limite na abordagem de conceitos científicos (GALIAN, 2011).

A análise no periódico Educação e Pesquisa reafirma o que foi exposto anteriormente, no sentido de que estão sendo desenvolvidos poucos estudos envolvendo a análise de currículos de Ciências em nosso país, com enfoque nos pressupostos sociológicos de Basil Bernstein. O estudo também evidenciou que, nas pesquisas desenvolvidas no período de 2010 a 2014 por Galian $(2011,2012)$, o processo de recontextualização do conhecimento científico apresentou uma redução, com perda conceitual acentuada em relação ao saber de onde provém o DPO das Ciências Naturais. 
Figura 2. A recontextualização e o nível de exigência conceitual do conhecimento escolar

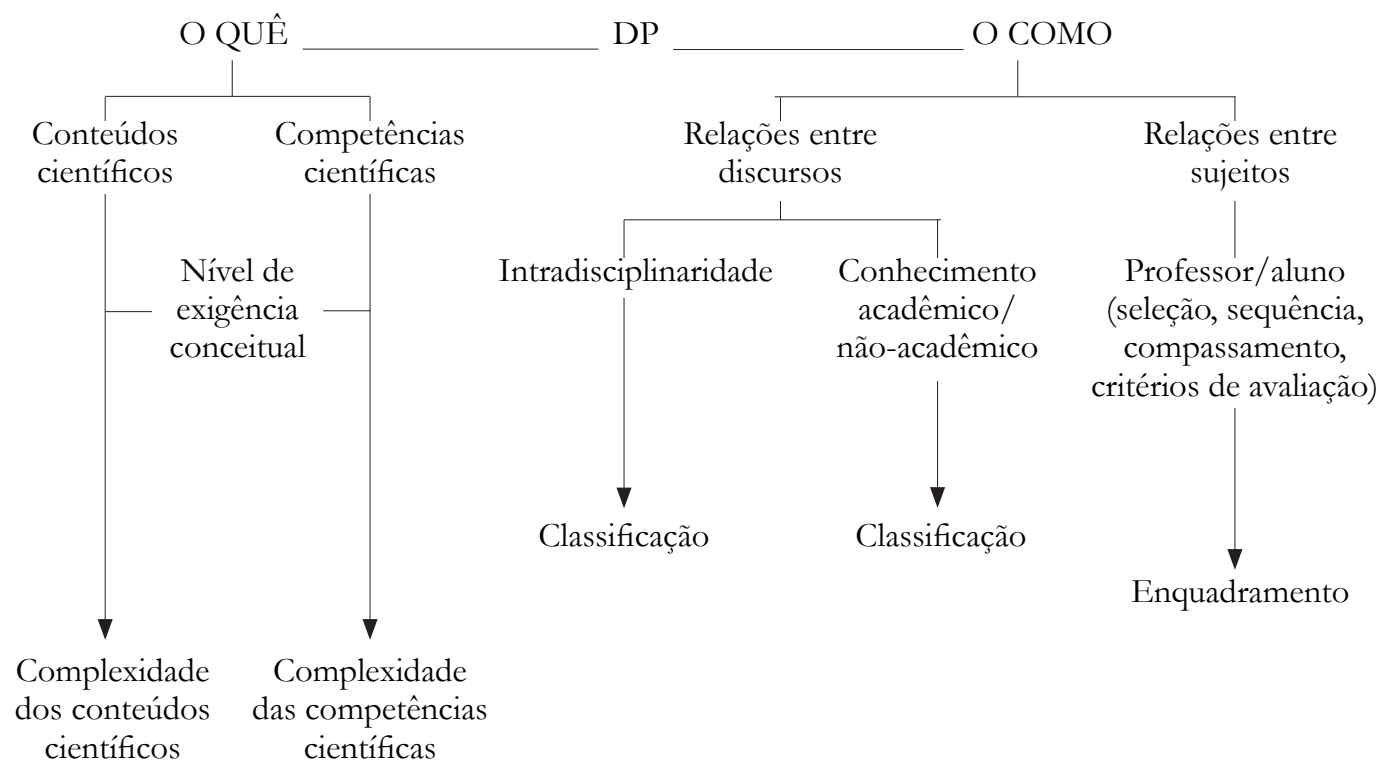

Fonte: Galian (2011, p. 770).

\section{Considerações finais}

Este estudo verificou a utilização dos pressupostos sociológicos de Bernstein na análise de currículos de Ciências. Os resultados demonstram que, no período de 2010 a 2014, o grupo de ESSA, da Universidade de Lisboa, realizou o maior número de pesquisas sobre o tema e orientou os estudos desenvolvidos em nosso país, no mesmo período. Boa parte dos trabalhos analisados contempla o Ensino de Ciências de Ensino Fundamental, sendo que seis das sete publicações analisadas tiveram esse enfoque. Apenas uma das pesquisas analisadas foi desenvolvida com foco na formação de professores e em aspectos apresentados na teoria de Bernstein. Verificou-se, também, que o conceito de recontextualização apresentado por Bernstein é o mais presente nas pesquisas analisadas, seguido pelas ideias DPO, DPR, discurso vertical e discurso horizontal.

No Brasil, mesmo após a elaboração de importantes documentos que influenciam no DPR, como os PCN, os PCNEM e diretrizes que orientam a formação docente para o exercício na Educação Básica, poucas análises de currículos de Ciências na Educação Básica e em nível superior têm sido realizadas, indicando que estudos voltados a esse aspecto devem ser desenvolvidos. A teoria do dispositivo pedagógico permite a análise profunda do Ensino de Ciências da Natureza, contemplando desde o estudo de diretrizes curriculares e documentos educacionais ao contexto de sala de aula e espaços informais de aprendizagem, como museus. 
A teoria também possibilita a investigação de fatores que influenciam no processo de ensino -aprendizagem, como: a relação entre professor e aluno, o processo avaliativo da aprendizagem, o discurso presente nos materiais didáticos utilizados, a interdisciplinaridade entre diferentes áreas do conhecimento e a relação entre a comunidade e a escola. Dessa forma, as ideias de Bernstein oferecem valorosas contribuições nas investigações da área do ensino.

Os estudos desenvolvidos em Portugal se preocuparam em investigar a recontextualização do DPO nos documentos elaborados após a reestruturação curricular do ensino básico, que se deu no ano de 2001. Os resultados das pesquisas desenvolvidas pelo grupo de ESSA apontam a necessidade de incentivo à formação docente continuada, devido à verificação da diminuição da complexidade dos conhecimentos científicos e das competências investigativas na recontextualização do DPO para as práticas desenvolvidas em sala de aula. O mesmo foi apurado nas pesquisas desenvolvidas em nosso país.

Outro dado importante da pesquisa desenvolvida no Brasil (GALIAN, 2011) se refere à configuração de um contexto não favorável ao desenvolvimento do pensamento complexo, em decorrência da compartimentação dos saberes em componentes curriculares, sem a busca pela inter-relação existente entre as diferentes áreas do conhecimento, demonstrando, segundo Bernstein, que há uma classificação forte no currículo. Para a superação deste fato, os documentos educacionais, os cursos de licenciaturas e eventos da área da Educação vêm intensificando o debate sobre o desenvolvimento de práticas interdisciplinares no trabalho escolar, em que os conhecimentos possam ser construídos pelos alunos de forma não fragmentada. Porém, o desenvolvimento de atividades interdisciplinares no contexto educacional encontra barreiras ao ser implementado, como a falta de formação docente continuada e o curto período destinado ao planejamento na carga horária dos professores. Essa análise também revelou que os conhecimentos prévios dos alunos têm sido o limite para a abordagem dos conceitos científicos, e não o ponto de partida para o trabalho a ser desenvolvido em sala de aula. A escola é o espaço em que a cultura e o conhecimento devem ser vivenciados e construídos, assim, quando esse ambiente trabalha apenas com saberes que os alunos já possuem, sua função acaba não sendo exercida.

\section{Referências}

ALVES, V.; MORAIS, A. M. Currículo e práticas pedagógicas: uma análise sociológica de textos e contextos da educação em ciências. Revista Portuguesa de Educação, Lisboa, v. 26, n. 1, p. 219-251, 2013.

AL-RAMAHI, N.; DAVIES, B. Changing primary education in Palestine: pulling in several directions at once. International Studies in Sociology of Education, Abingdon, v. 12, n. 1, p. 59-76, 2002.

BERNSTEIN, B. Class, codes and control. London: Routledge \& Kegan Paul, 1977. v. 3. Class, codes and control: the structuring of pedagogic discourse. London:

Routledge, 1990. 
Análise de currículos de ciências à luz da teoria de Bernstein

BERNSTEIN, B. A estruturação do discurso pedagógico: classes, códigos e controle. Petrópolis: Vozes, 1996.

. Pedagogia, control simbólico e identidad. Madrid: Morata, 1998.

- Vertical and horizontal discourse: an essay. British Journal of Sociology of Education, Abingdon, v. 20, p. 157-173, 1999.

Pedagogy, symbolic control and identity: theory, research, critique. New York: Rowman \& Little, 2000.

BRASIL. Conselho Nacional de Educação. Resolução no 2, de 1 julho de 2015. Define as diretrizes curriculares nacionais para a formação inicial em nível superior (cursos de licenciatura, cursos de formação pedagógica para graduados e cursos de segunda licenciatura) e para a formação continuada. Brasília, 2015.

BRASIL. Ministério da Educação. Diretrizes curriculares nacionais gerais da educação básica. Brasília, 2013.

Guia de livros didáticos: PNLD 2005. Brasília, 2004.

. Orientações complementares aos parâmetros curriculares nacionais: ciências da natureza, matemática e suas tecnologias. Brasília, 2002.

Parâmetros curriculares nacionais: ciências naturais $-3 .^{\circ}$ e $4 .^{\circ}$ ciclos do ensino fundamental. Brasília, 1998.

Parâmetros curriculares nacionais do ensino médio: ciências da natureza, matemática e suas tecnologias. Brasília, 2000.

CALADO, S.; NEVES, I. P. Currículo e manuais escolares em contexto de flexibilidade curricular: estudo de processos de recontextualização. Revista Portuguesa de Educação, Lisboa, v. 12, n. 1, p. 53-93, 2012.

FERREIRA, S.; MORAIS, A. M. A natureza da ciência nos currículos de ciências: estudo do currículo de ciências naturais do $3 .^{\circ}$ ciclo do ensino básico. Revista Portuguesa de Educação, Lisboa, v. 23, n. 1, p. 119-156, 2010.

GALIAN, C. V. A prática pedagógica e a criação de um contexto favorável para a aprendizagem de ciências no ensino fundamental. Ciência \& Educação, Bauru, v. 18, n. 2, p. 419-433, 2012.

A recontextualização e o nível de exigência conceitual. Educação e Pesquisa, São Paulo, v. 37, n. 4, p. 763-778, 2011.

GIL, A. C. Como elaborar projetos de pesquisa. 4. ed. São Paulo: Atlas, 2007.

LOPES, A. C. Políticas de currículo: recontextualização e hibridismo. Currículo sem Fronteiras, v. 6, n. 2, p. 50-64, jul./dez. 2005.

LUNA, M. V. El paradigma de la complejidad en discursos sobre formación docente en ciências. Ciência \& Educação, Bauru, v. 20, n. 4, p. 971-986, 2014. 
Coelho, F. B. O.

MAINARDES, J.; STREMEL, S. A teoria de Basil Bernstein e algumas de suas contribuições para as pesquisas sobre políticas educacionais e curriculares. Revista Teias, Rio de Janeiro, v. 11, n. 22, p. 31-54, 2010.

MARANDINO, M. Transposição ou recontextualização?: sobre a produção de saberes na educação em museus de ciências. Revista Brasileira de Educação, Rio de Janeiro, n. 26, p.95-108, maio/jun./jul./ago. 2004.

SILVA, T. T. da. Documentos de identidade: uma introdução às teorias do currículo. 2. ed. Belo Horizonte: Autêntica, 2000.

SILVA, P.; MORAIS, A. M.; NEVES, I. P. O currículo de ciências no $1^{\circ}$ ciclo do ensino básico: estudo de (des)continuidades na mensagem pedagógica. Revista Portuguesa de Educação, Lisboa, v. 1, n. 26, p. 179-217, 2013.

UNIVERSITAS: a produção científica sobre educação superior no Brasil, 1968-2000. Porto Alegre: GT Política de Educação Superior: ANPED, 2002. Disponível em: <http:// www:pucrs.br/faced/pos/universitas>. Acesso em: 5 nov. 2015.

Artigo recebido em 09/03/2016. Aceito em 15/11/2016.

Endereço para contato: Universidade Federal do Pampa, Dom

Pedrito, RS, Brasil. 